\title{
Relationship Between Geometrical Structure and Acid Properties \\ of Exhaustively Substituted Nitrosophenols with Pyridine Substituents
}

\author{
Aleksey A. Kukushkin , \\ Pavel O. Krasnov ${ }^{\mathrm{a}, \mathrm{b}}$, Evgeniy V. Root ${ }^{\mathrm{a}, \mathrm{c}}$, \\ Georgy A. Suboch and Mikhail S. Tovbis*a \\ ${ }^{a}$ Reshetnev Siberian State University of Science and Technology \\ 31 Krasnoyarskiy rabochiy, Krasnoyarsk, 660037, Russia \\ ${ }^{b}$ Siberian Federal University \\ 79 Svobodny, Krasnoyarsk, 660041, Russia \\ ${ }^{c}$ Krasnoyarsk State Medical University \\ named after Prof. V.F. Voino-Yasenetsky \\ 1 Partizana Zheleznyaka, Krasnoyarsk, 660022, Russia
}

Received 16.10.2017, received in revised form 12.11.2017, accepted 30.11.2017

The acidity constants of the exhaustively substituted nitrosophenols with phenyl and ester substituents are determined. It was found that these compounds are more acidic than nitrosophenols with methyl groups, but less acidity than the persubstituted nitrosophenols with pyridine substituents. Quantumchemical calculations, performed by the method of stationary density functional theory using exchangecorrelation functional BP86 and def2-SVP basis set, have shown that the pyridine and nitrosophenol rings occupy an intermediate position between the orthogonal and coplanar functional. Thus, the hypothesis of a possible electron-withdrawing effect of the nitrogen atom of pyridine rings not only through the system of $\sigma$-bonds, but also due to the mesomeric effect through the residual coupling of $\pi$-systems is confirmed.

Keywords: exhaustively substituted nitrosophenols, acidity constant, pyridine substituents, quantum chemical calculations, coplanarity, orthogonality.

DOI: 10.17516/1998-2836-0050.

(C) Siberian Federal University. All rights reserved

* Corresponding author E-mail address: tovbis@bk.ru 


\title{
Связь между геометрическим строением
}

\section{и кислотными свойствами перзамещенных нитрозофенолов с пиридиновыми заместителями}

\author{
А.А. Кукушкин ${ }^{\mathrm{a}}$ П.О. Краснов ${ }^{\mathrm{a}, \tilde{\sigma}}$, \\ Е.В. Роот ${ }^{\text {a,s }}$, Г.А. Субоч ${ }^{\text {a }}$ М.С. Товбис ${ }^{\mathrm{a}}$ \\ ${ }^{a}$ Сибирский государственныц̆ университет науки и технологий \\ им. академика М.Ф. Решетнева \\ Россия, 660037, Красноярск, пр. Красноярский рабочий, 31 \\ ${ }^{6}$ Сибирский федеральный университет \\ Россия, 660041, Красноярск, пр. Свободный, 79 \\ ${ }^{8}$ Красноярский государственный медицинский университет \\ им. проф. В.Ф. Войно-Ясенецкого \\ Россия, 660022, Красноярск, ул. Партизана Железняка, 1
}

Определены константы кислотности перзамещенных нитрозофенолов с фенильным и сложноэфирными заместителями. Установлено, что эти соединения обладают большей кислотностью, чем нитрозофеноль с метильными группами, но меньшей кислотностью, чем перзамещенные нитрозофенолы с пиридиновыми заместителями. Квантово-химические расчеты, выполненные методом стационарной теории функционала плотности с использованием обменно-корреляциионного функционала ВР86 и базисного набора атомных орбиталей def2-SVP, показали, что пиридиновые и нитрозофенольное кольца занимают промежуточное расположение между ортогональным и копланарным. Таким образом, подтверждена гипотеза о возможном электроноакцепторном влиянии атома азота пиридиновых цииклов не только через систему б-связей, но и за счет мезомерного эффекта через остаточное сопряжение $\pi$-систем.

Ключевые слова: перзамещценные нитрозофеноль, константа кислотности, пиридиновые заместители, квантово-химические расчеты, копланарность, ортогональность.

\section{Введение}

Известны полностью замещенные пара-нитрозофенолы, которые получают по реакции циклизации изонитрозо- $\beta$-дикетонов с эфирами ацетондикарбоновой кислоты [1]:<smiles>[R]C(=O)C(=N)C(C)=O</smiles><smiles>[R]OC(=O)CC(=O)CC(=O)O[R]</smiles><smiles>[R]OC(=O)c1c([R1])c([N+](=O)[O-])c(C)c(C(=O)O[R])c1[OH2+]</smiles>

(I) 
где $\mathrm{R}_{1}=\mathrm{Me}, \mathrm{R}=\mathrm{Me}$, Et, $\mathrm{Pr}, \mathrm{Bu}$, i-Bu, Am, i-Am.

Такие перзамещенные нитрозофенолы существуют преимущественно в нитрозоформе и димеризуются по типу азодиоксидов, подобно нитрозобензолам [1]. Константы кислотности, определенные для полностью замещенных нитрозофенолов, оказались в интервале 5,33-5,35 [2], в то время как для незамещенного нитрозофенола кислотность намного ниже, $\mathrm{pKa}=6,36[3]$.

Недавно были синтезированы нитрозофенолы (I) с $\alpha$-, $\beta$ - и $\gamma$-пиридиновыми заместителями $\mathrm{R}_{1}$ и $\mathrm{R}=\mathrm{Me}$, Et [4]. Константы их кислотности были измерены, значения $\mathrm{pКа} \mathrm{составили}$ 4,10-4,62 [5]. Иными словами, нитрозофенолы с пиридиновыми заместителями оказались кислее на порядок. Для объяснения такого существенного повышения кислотности было высказано предположение, что пиридиновые заместители влияют на кислотность не только за счет отрицательного индуктивного влияния пиридинового кольца, но и благодаря отрицательному мезомерному эффекту. Именно отрицательный мезомерный эффект, т.е. передача влияния пиридинового атома азота через общую сопряженную $\pi$-систему пиридин-бензол, может приводить к увеличению кислотности в ряду нитрозофенолов (I) с $\beta$-, затем $\alpha$ - и наконец $\gamma$-пиридиновыми заместителями. Для корректного сравнения не хватало кислотности не синтезированных до настоящего времени нитрозофенолов (I) с заместителями $\mathrm{R}_{1}=\mathrm{Ph}$ и $\mathrm{R}=\mathrm{Me}$, Et. Важно было и найти подтверждение сопряжения в системах пиридин-бензол и бензол-бензол.

Поэтому целью настоящего исследования стало определение кислотности фенилзамещенных нитрозофенолов (I) и проведение компьютерных расчетов для построения моделей, позволяющих оценить степень копланарности нитрозофенольного кольца с пиридиновыми и фенильным заместителями.

\section{Материалы и методы}

Определение $\mathrm{pK}_{\mathrm{a}}$ 2,6-ди(алкоксикарбонил)-3,5-дизамещенных-4-нитрозофенолов проводили спектрофотометрическим методом [6] при температуре $(25 \pm 0,1){ }^{\circ} \mathrm{C}$, в цитратных буферных растворах [7]. Этот метод оказался подходящим для определения $\mathrm{pK}_{\mathrm{a}}$, т.к. спектры перзамещенных нитрозофенолов с пиридиновыми заместителями и их анионов существенно различаются. Аналитическая длина волны для измерений $\lambda_{\text {мах }}$ составила 395 нм. Именно на этой длине волны наблюдается максимальное поглощение нитрозофенолят-ионов в щелочной среде, в то же время недиссоциированная форма в этой области имеет весьма малый коэффициент молярной экстинкции. Поэтому разность в поглощении для двух форм велика, что создает идеальные условия для определения ионизационного отношения.

Оптическую плотность растворов нитрозофенолов определяли на спектрофотометре «Helios» Omega в кварцевых кюветах 1 см в интервале длин волн от 320 до 510 нм.

Для определения рКа готовили спиртовые растворы нитрозофенолов с таким расчетом, чтобы после разбавления рабочая концентрация составляла $10^{-4}$ моль/л.

На спектрофотометре получали график зависимости оптической плотности (D) от длины волны (ג). Определяли аналитическую длину волны для каждого нитрозофенола. Затем готовили серию цитратных буферных растворов, в которых и проводили определение рКа гексазамещенных пара-нитрозофенолов. 
По полученным данным строили графики в координатах $\lg$ I - pH для каждого из новых фенилзамещенных napa-нитрозофенолов. Константу кислотности определяли как точку пересечения линейной зависимости с осью $\mathrm{pH}$ (графический метод), в результате получали приближенное значение $\mathrm{pKa}$. Аналитически значения $\mathrm{pKa} \mathrm{рассчитывали} \mathrm{как} \mathrm{разность} \mathrm{между} \mathrm{pH}$ и $\lg \mathrm{I}$ (логарифмом ионизационного отношения). После вычисления дисперсии по формуле

$$
\sigma=\sqrt{\frac{\sum_{n}^{i=1}\left(\Delta p K a_{i}\right)^{2}}{n(n-1)}}
$$

с учетом принятого уровня вероятности $\alpha=0,95$ находили табличное значение критерия Стьюдента $(\mathrm{t}=2,45)$ и вычисляли абсолютную ошибку $\Delta \mathrm{pKa}=\mathrm{t} \times \sigma$.

Геометрическое строение рассматриваемых молекул оценивали посредством квантовохимических вычислений методом стационарной теории функционала плотности (DFT) с использованием обменно-корреляционного функционала ВР86 [8, 9], базисного набора атомных орбиталей def2-SVP [10, 11] и полуэмпирического дисперсионного потенциала Grimme [12, 13] в программном пакете ORCA [14]. При этом дополнительно после оптимизации геометрии осуществлялся расчёт их колебательных спектров с использованием RI-приближения [15-21]. Отсутствие отрицательных частот в данных спектрах указывает на то, что молекулярная структура исследуемых соединений действительно соответствует их равновесному строению.

\section{Результаты и обсуждение}

Значение рКа для фенилзамещенного нитрозофенола с этоксикарбонильными группами составило $4,75 \pm 0,04$, а для нитрозофенола с метоксикарбонильными группами $-4,72 \pm 0,04$, т.е. полученные значения находятся между таковыми для пиридинового и метильного заместителей.

В результате проведённых вычислений показано (рис. 1), что расположение пиридинового и фенольного колец друг относительно друга не является ни копланарным, ни ортогональным. Абсолютное значение торсионного угла $\theta(\mathrm{C} 1 \mathrm{C} 2 \mathrm{C} 3 \mathrm{C} 4)$ (рис. 2) между ними находится в диапазоне от 47,3 до $56,7^{\circ}$ либо от 125,5 до $128,7^{\circ}$ (табл. 1 ).

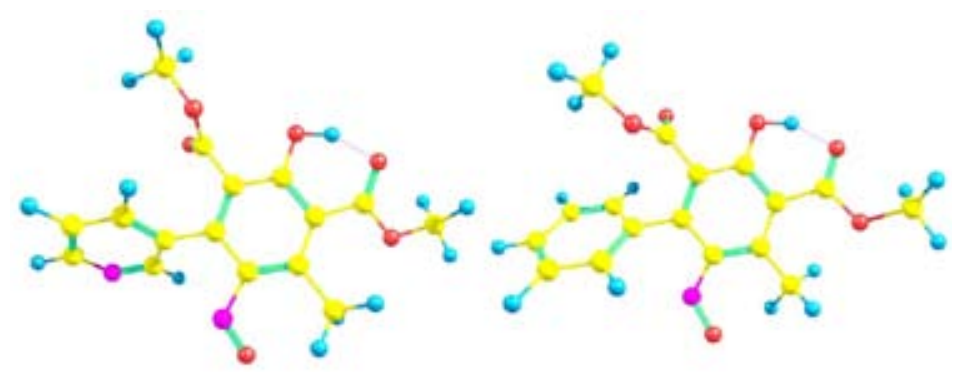

Рис. 1. Геометрическое строение 2,6-ди(метоксикарбонил)-3-метил-5-пиридин-3-ил-4-нитрозофенола и 2,6-ди(метоксикарбонил)-3-метил-5-фенил-4-нитрозофенола

Fig. 1. Geometric structure of 2,6-di(methoxycarbonyl)-3-methyl-5-pyridin-3-yl-4-nitrosophenol and 2,6-di(methoxycarbonyl)-3-methyl-5-phenyl-4-nitrosophenol

$$
-583-
$$


<smiles>[R2]OC(=O)C1=[Ge]([Ge]2C=CN=C[C]2N=O)C(C)=C(O)C(C([R20])=O)=C1O</smiles>

$\mathrm{R}=\mathrm{C}_{2} \mathrm{H}_{4}: 2,6$-ди(этоксикарбонил)-3-метил5-пиридин-4-ил-4-нитрозофенол (Структура 1) $\mathrm{R}=\mathrm{CH}_{3}: 2,6-д и$ (метоксикарбонил)-3-метил5-пиридин-4-ил-4-нитрозофенол (Струкмура 2)<smiles>[R]OC(=O)C1=C(O)C(C(=O)O)=C(C)[C]([Ge]2C=CC=N2)[C]1[N+](=O)[O-]</smiles>

$\mathrm{R}=\mathrm{C}_{3} \mathrm{H}_{4}: 2,6-$-ди(этоксикарбонил)-3-метил5-пиридин-2-ил-4-нитрозофенол (Структура 5) $\mathrm{R}=\mathrm{CH}_{1}: 2,6$-ди(метоксикарбонил)-3-метил5-пиридин-2-ил-4-нитрозофенол (Структура 6)<smiles>[R2]OC(=O)C1=[Ge]([Ge]2=C=CN=C=C2)[C](N=O)C(C)C(C([R20])=O)=C1O</smiles>

$\mathrm{R}=\mathrm{C}_{2} \mathrm{H}_{3}: 2,6$-ди(этоксикарбонил)-3-метил5-пиридин-3-ил-4-нитрозофенол (Структура 3) $\mathrm{R}=\mathrm{CH}_{3}: 2$,6-ди(метоксикарбонил)-3-метил5-пиридин-3-ил-4-нитрозофенол (Структура 4)<smiles>[R]OC(=O)C1=C([Ge]2C=CC=C[Cl+]2)[C](C)C(=O)C(C([R20])=O)=C1O</smiles>

$\mathrm{R}=\mathrm{C}_{2} \mathrm{H}_{4} ; 2,6-$ ди (этоксикарбонил)-3-метил5-фенил-4-нитрозофенол (Струкпура 7) $\mathrm{R}=\mathrm{CH}_{3}: 2,6-д и$ (метоксикарбонил)-3-метил5-фенил-4-нитрозофенол (Струкпура 8)

Рис. 2. Структурные формулы рассматриваемых соединений

Fig. 2. The structural formula of the studied compounds

Таблица 1. Значения торсионных углов в рассматриваемых соединениях

Table 1. Values of torsion angles in the studied compounds

\begin{tabular}{|c|c|}
\hline Соединение & $\begin{array}{c}\theta(\mathrm{C} 1 \mathrm{C} 2 \mathrm{C} 3 \mathrm{C} 4), \\
\text { градусы }\end{array}$ \\
\hline Структура 1 & 125,5 \\
\hline Структура 2 & 126,0 \\
\hline Структура 3 & 128,3 \\
\hline Структура 4 & 128,7 \\
\hline
\end{tabular}

\begin{tabular}{|c|c|}
\hline Соединение & $\begin{array}{c}\theta(\mathrm{C} 1 \mathrm{C} 2 \mathrm{C} 3 \mathrm{C} 4), \\
\text { градусы }\end{array}$ \\
\hline Структура 5 & 52,2 \\
\hline Структура 6 & 47,3 \\
\hline Структура 7 & 56,7 \\
\hline Структура 8 & 55,0 \\
\hline
\end{tabular}

Из полученных экспериментальных данных видно, что введение фенильного заместителя вместо метильной группы увеличивает кислотность перзамещенных нитрозофенолов (среднее рКа 4,75 вместо 5,34). Эти данные укладываются в общую концепцию кислотности органических соединений, согласно которой увеличение электроотрицательности заместителя (фенил с $\mathrm{sp}^{2}$-гибридизацией углеродных атомов вместо метила с $\mathrm{sp}^{3}$-гибридными атомами углерода) приводит к стабилизации нитрозофенолят-иона и, как следствие, к увеличению кислотности.

При введении пиридинового остатка происходит еще большее увеличение кислотности, до значений рКа 4,10-4,62. Это происходит как за счет передачи индуктивного влияния пиридинового атома азота по системе $\sigma$-связей, так и за счет передачи отрицательного мезомерного эффекта через $\pi$-системы пиридин-бензол, для которой, как это подтвердили расчеты, сохранено хотя и не копланарное, но далекое от ортогональности расположение колец. 


\section{Выводы}

1. Определены константы кислотности перзамещенных нитрозофенолов с фенильным и сложноэфирными заместителями, которые оказались больше, чем для нитрозофенолов с метильными группами, но меньше, чем для перзамещенных нитрозофенолов с пиридиновыми заместителями.

2. Квантово-химические расчеты показали, что пиридиновые и нитрозофенольное кольца занимают промежуточное расположение между ортогональным и копланарным.

3. Подтверждено мезомерное влияние атома азота через сохранившееся сопряжение нитрозофенольного и пиридинового ядер.

\section{Список литературы}

1. Slaschinin D.G., Alemasov Yu.A., Tovbis M.S., Kirik S.D. X-Ray diffraction and spectroscopic verification of dimerization in hexasubstituted para-nitrosophenols. Journal of Molecular Structure. 2011. Vol. 985. P. 184-190.

2. Слащинин Д.Г., Кукушкин А.А., Товбис М.С. Кислотность новых гексазамещенных $n$-нитрозофенолов. ЖОрХ 2011. Т. 47. Вып. 9. С. 1406. [Slashchinin D.G., Kukushkin A.A., Tovbis M.S. Acidity of New Exhaustively Substituted p-Nitrosophenols. Journal of Organic Chemistry 2011, Vol. 47, No. 9, p.1432].

3. Fickling M.M., Fisher A., Mann B.R., Packer J., Vaughan J. Hammett substituent constants for electronwithdrawing substituents: dissociation of phenols, anilinium ions and dimethylanilinium ions. J. Amer. Chem. Soc. 1959. V.81, №16. P. 4226-4230.

4. Kukushkin A.A., Root E.V., Tovbis M.S., Suboch G.A., Kondrasenko A.A. Synthesis of potassium 2,6-di(alkoxycarbonyl)-3-methyl-4-nitroso-5-[pyridin-3(4)-yl]phenolates Russian Journal of Organic Chemistry. 2015. T. 51. №5. P. 733-734.

5. Кукушкин А.А., Привалихина А.П., Роот Е.В., Слащинин Д.Г., Субоч Г.А., Товбис М.С. Кислотность перзамещенных пара-нитрозофенолов, содержащих пиридиновый заместитель. Успехи современного естествознания, 2017, Вып. 6, С. 53-61.[ A.A. Kukushkin, A.P. Privalikhina, Ye.V. Root, D.G. Slashchinin, G.A. Suboch, M.S. Tovbis. Kislotnost' perzameshchennykh paranitrozofenolov, soderzhashchikh piridinovyy zamestitel'. Uspekhi sovremennogo yestestvoznaniya, 2017, vyp. 6, P. 53-61. (in Russ.)]

6. Альберт А., Сержент Е. Константы ионизации кислот и оснований. М.: Химия, 1964. 180 c. [Albert A., Serzhent E. The ionization constants of acids and bases. Moscow: Khimia, 1964. 180 p. (in Russ)]

7. Швабе К. Основы техники измерения рН. М.: Издатинлит, 1962, 472 с. [Shvabe K. Basics of measuring pH. Moscow: Izdatinlit, 1962. 472 p. (in Russ)]

8. Becke A.D. Density-functional exchange-energy approximation with correct asymptotic behavior. Physical Review A 1988. Vol. 38(6), P. 3098-3100.

9. Perdew J.P. Density-functional approximation for the correlation energy of the inhomogeneous electron gas. Physical Review B 1986. Vol. 33(12), P. 8822-8824.

10. Schäfer A., Horn H., Ahlrichs R. Fully optimized contracted Gaussian basis sets for atoms Li to Kr. The Journal of Chemical Physics 1992. Vol. 97(4), P. 2571-2577.

$$
-585-
$$


11. Schäfer A., Huber C., Ahlrichs R. Fully optimized contracted Gaussian basis sets of triple zeta valence quality for atoms Li to Kr. The Journal of Chemical Physics 1994. Vol. 100(8), P. 58295835 .

12. Grimme S., Ehrlich S., Goerigk L. Effect of the damping function in dispersion corrected density functional theory. Journal of Computational Chemistry 2011. Vol. 32(7), P. 1456-1465.

13. Grimme S., Antony J., Ehrlich S., Krieg H. A consistent and accurate ab initio parametrization of density functional dispersion correction (DFT-D) for the 94 elements H-Pu. The Journal of Chemical Physics 2010. Vol. 132(15), 154104.

14. Neese F. The ORCA program system. Wiley Interdisciplinary Reviews: Computational Molecular Science 2012. Vol. 2(1), P. 73-78.

15. Baerends E.J, Ellis D.E., Ros P. Self-consistent molecular Hartree-Fock-Slater calculations I. The computational procedure. Chemical Physics 1973. Vol. 2(1), P. 41-51.

16. Dunlap B.I., Connolly J.W.D., Sabin J.R. On some approximations in applications of $X \alpha$ theory. The Journal of Chemical Physics 1979. Vol. 71(8), P. 3396-3402.

17. Van Alsenoy C. Ab initio calculations on large molecules: The multiplicative integral approximation. Journal of Computational Chemistry 1988. Vol. 9(6), P. 620-626.

18. Kendall R.A, Früchtl H.A. The impact of the resolution of the identity approximate integral method on modern ab initio algorithm development. Theoretical Chemistry Accounts 1997. Vol. 97(14), P. 158-163.

19. Eichkorn K., Treutler O., Öhm H., Häser M., Ahlrichs R. Auxiliary basis sets to approximate Coulomb potentials. Chemical Physics Letters 1995. Vol. 240(4), P. 283-290.

20. Eichkorn K., Weigend F., Treutler O., Ahlrichs R. Auxiliary basis sets for main row atoms and transition metals and their use to approximate Coulomb potentials. Theoretical Chemistry Accounts 1997. Vol. 97(1-4), P. 119-124.

21. Whitten J.L. Coulombic potential energy integrals and approximations The Journal of Chemical Physics 1973. Vol. 58(10), P. 4496-4501. 